\title{
Strategic Marketing for the Vietnamese Dragon Fruit
}

\author{
Nguyen Thanh Nguyen \\ Doctor, Lecturer of Graduate School \\ Ho Chi Minh City Open University, Vietnam
}

\begin{abstract}
The dragon fruit is a strong agricultural product of Vietnam; however, its market faces instability, which can cause crisis and damages to farmers. The paper studies the current problems with the product and proposes strategic marketing methods that aim to promote its sustainable development.
\end{abstract}

Key words: marketing, dragon fruit, production, price, promotion, quality

\section{Summary Statement of Contribution}

The Vietnamese dragon fruit is Vietnam's largest exportation product. However, the business is facing crisis because of uncontrolled development and poor marketing. The paper analyses the current marketing of this agricultural product. Based on the study and experience, the author proposes marketing methods and policies to maintain the stable development of the dragon fruit as a product. The paper is helpful for the government, farmers, enterprises, and market researchers of the dragon fruit business.

\section{INTRODUCTION}

Dragon fruit is now the main agricultural product of Vietnam. According to the Vietnam Fruit and Vegetables Association (VINAFRUIT), dragon fruit exportation represents one-third of the country's total fruit export value. However, its production and exportation are facing many difficulties.

Dragon fruit comes from a fruit tree (Hylocereus or pitahaya, pitaya) that is a cactus and grows naturally in Middle and South America. The Vietnamese people planted this kind of tree a hundred year ago, but dragon fruit has become a favorite fruit in the last two decades and is currently a strong exportation fruit of Vietnam. While there are many kinds of dragon fruit, there are two main genera in Vietnam (Hylocereus undatus and Hylocereus polyrhizus). The dragon fruit is highly nutritious and good for people's health (see Table 1) (Li Chen Wu et al, 2016). In addition, the color and shape of the fruit are attractive to Asian people. In particular, the Chinese like the red color, dragon shape and brix level of the fruit.

Dragon fruit has gradually become popular worldwide, and it grows in dozens of countries: Israel, Malaysia, Indonesia, Myanmar, Philippines, Taiwan, Thailand, China, the USA, Australia, Sri Lanka, and Middle American countries. However, Vietnam exports the largest quantity commercially to more than 40 countries, and the Vietnamese pitaya occupies the largest market share in the international market. 
In Vietnam, dragon fruit is cultivated mainly in three provinces: Binh Thuan, Tien Giang, and Long An. The agricultural production scale amounts to more than fifty thousand hectares, and the annual output can reach approximately one million tons (2017). Eighty percent of production serves for exportation (mostly fresh fruit), and the value and quantity have grown quickly (see Figure 1), with the market concentrated on China, Japan, the USA, Australia, and the EU.

There are two main types of dragon fruit in Vietnam: red peel-white flesh (H. undatus) and red peel-red flesh (H. polyrhizus). In comparison with the dragon fruit of other countries, the Vietnamese pitaya has a balance of protein, fat, ash, vitamin, sugar and mineral (see Table 1). This quality attracts consumers from many countries.

Vietnamese dragon fruit production is quickly increasing. Dragon fruit plantation areas grow rapidly because by growing dragon fruit, farmers can gain five to ten times the income gained from rice cultivation. However, this trend can trigger surplus, and the price can decrease sharply. In Vietnam, this event frequently occurs for products such as watermelon, banana, passion fruit, jack fruit and cashew nut. The price of pitaya fluctuates along with the volume of this fruit available in the market, and it usually decreases around the time of the natural crop (from June to September). This can reduce farmers' income.

Table 1: Nutrition facts of red flesh dragon fruit

\begin{tabular}{|c|c|c|c|}
\hline Composition & $/ \mathbf{1 0 0} \mathbf{g}$ flesh & Composition & $/ \mathbf{1 0 0}$ g flesh \\
\hline Moisture & $87.3 \pm 0.02(\mathrm{~g})$ & Iron & $3.4 \pm 0.25(\mathrm{mg})$ \\
\hline Ask & $0.7 \pm 0.03(\mathrm{~g})$ & Zinc & $13.87 \pm 0.65(\mathrm{mg})$ \\
\hline Protein & $0.16 \pm 0.02(\mathrm{~g})$ & Copper & $0.031 \pm 0.004(\mathrm{mg})$ \\
\hline Fat & $0.23 \pm 0.03(\mathrm{~g})$ & Thiamin & $48.9 \pm 1.56(\mu \mathrm{g})$ \\
\hline Carbohydrate & $1.48 \pm 0.15(\mathrm{~g})$ & Riboflavin & $40.75 \pm 3.47(\mu \mathrm{g})$ \\
\hline Crude fiber & $10.1 \pm 0.25(\mathrm{~g})$ & Niacin & $513.78 \pm 6.53(\mu \mathrm{g})$ \\
\hline Calcium & $5.7 \pm 0.08(\mathrm{mg})$ & Pyridoxine & $20.57 \pm 2.23(\mu \mathrm{g})$ \\
\hline Phosphorus & $23 \pm 0.04(\mathrm{mg})$ & Cobalamin & $15.61 \pm 1.89(\mu \mathrm{g})$ \\
\hline Magnesium & $28.3 \pm 0.97(\mathrm{mg})$ & Ascorbic acid & $10.32 \pm 1.1(\mathrm{mg})$ \\
\hline Sodium & $50.15 \pm 0.1(\mathrm{mg})$ & Vitamin A & $120.13 \pm 3.2(\mu \mathrm{g})$ \\
\hline Potassium & $56.96 \pm 0.02(\mathrm{mg})$ & Vitamin E & $105.67 \pm 4.15(\mu \mathrm{g})$ \\
\hline
\end{tabular}

Source: VINAFRUIT 


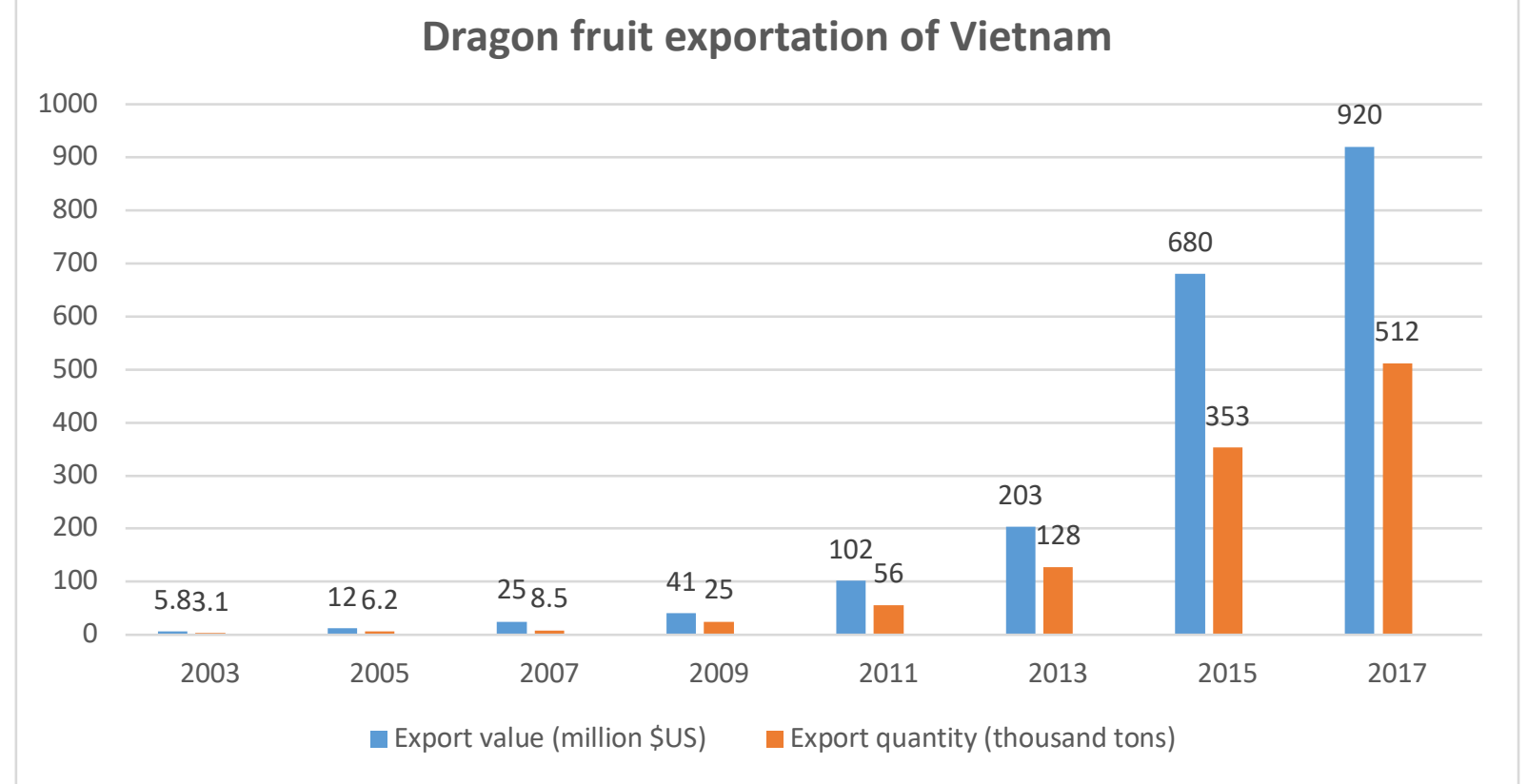

Source: MoIT

Figure 1: Dragon fruit exportation of Vietnam

There are many general studies about marketing, but marketing for an agricultural product is not easy due to the product's specific characteristics. Kotler and Keller (2016) suppose that the production of agricultural products in many developing countries is not coordinated with the consumption markets, which is a reason for product inhibition. Researchers have proven that promoting product distribution and consumption is one of the most important duties of marketing (Bucklin et al, 2008; Jordan Gamble et al, 2011). In the case of the Vietnamese dragon fruit, market enlargement is helpful to maintain production efficiency. The growers and traders of pitaya concentrate on building a trade name, securing a distribution system, and ensuring product quality. Trade name helps producers gain market share, attract consumers and build loyalty (Kotler and Armstrong, 2017). Although Vietnam is now the largest dragon fruit exporter, its producers have not yet built the brand name of pitaya. According to Schiffman and Kanuk (2004), customers' knowledge of and experience with the brand name are determinants of their selection and purchase; this is very useful knowledge for the dragon fruit business because the fruit is not very popular in the international market. In addition, a brand name needs to cooperate with a system of product distribution. If producers can build a trade name, secure distribution system and ensure product quality, the product will attract customers, and consumption and sale turnover will increase in the long term (Pekka Touminen, 1996). Product quality builds customer confidence and satisfaction (Valarie, 1988), especially when the product concerned is fruit, which is a food that directly impacts health. The diversification of fruit products is also important to maintain and develop the market share. In the case of dragon fruit, growers and producers need to develop many kinds of high-quality pitaya and related food and drink (Clarke et al, 2011).

\section{THE ADVANTAGES AND SHORTCOMINGS OF VIETNAMESE DRAGON FRUIT MARKETING} The marketing for pitaya products confronts many problems, especially in exportation markets. The rapid development of pitaya can cause bad consequences; the rubber tree, watermelon plantation, or basa catfish aquaculture are key examples of when supply overcomes demand. 
Frequently, the product price experiences a freefall, and farmers face the bitter result. Similarly, the marketing for the Vietnamese pitaya faces difficulties in terms of assuring stable development. Transportation and fruit preservation are also obstacles to dragon fruit trading. This analysis presents the advantages and shortcomings of the pitaya marketing of Vietnam.

\section{Production}

The attraction of high income in the pitaya business encourages Vietnamese farmers to change large rice fields into dragon fruit plantations. The national statistics show a sharp, ongoing increase in pitaya areas in Vietnam. This growth has helped Vietnam become a leader in the dragon fruit production and exportation worldwide (see Figure 1). The income from dragon fruit (which is more than five times higher than the income from a rice plantation) enables thousands of households to become well off. In addition, dragon fruit companies employ thousands of workers, providing a solution to rural poverty. Yearly pitaya exportation yields billions of dollars for the Vietnamese economy. However, uncontrolled growth can cause an imbalance between demand and supply and threaten national food policy.

Vietnamese farmers have good experience and apply many new technologies in pitaya plantations, which helps raise the quality and productivity of the fruit cultivation. For a short time, farmers used wooden pillars for the dragon fruit trees to climb, but currently, they use reinforced concrete pillars. They plant four pitaya trees around each pillar. When the main branches climb to the top of the pillar, the farmers bend them to disperse the sprigs and maintain the balance of the whole pillar (see Figure 2). In South Vietnam, farmers can plant 1000 to 1200 pillars per hectare at a depth of approximately 0.5 meter (depending on the stability of the pillar in the soil). Experience has shown that this density can achieve maximum productivity. Vietnamese farmers usually use stem cuttings of pitaya trees for a new plantation. They choose mature, strong, and healthy pitaya stems, cut them into short segments (approximately $30 \mathrm{~cm}$ ) and put them in a cool, shady place for 15 to 20 days. Then, they plant them in the field (see Figure 3). However, this planting method has some disadvantages: the pillar can collapse because of a storm or become unbalanced because of the weight of the twigs, and old twigs remain covered by the new twigs, which keeps them out of the light and makes them prone to disease. The average productivity of dragon fruit is approximately 30 to 50 tons per hectare; the ideal weight of the fruit is $0.3 \mathrm{~kg}$ to $0.5 \mathrm{~kg}$ (depending on the predilection of consumers). The fruit needs good appearance, bright red color, and bracts that remain green to assure the demand for exported dragon fruit.

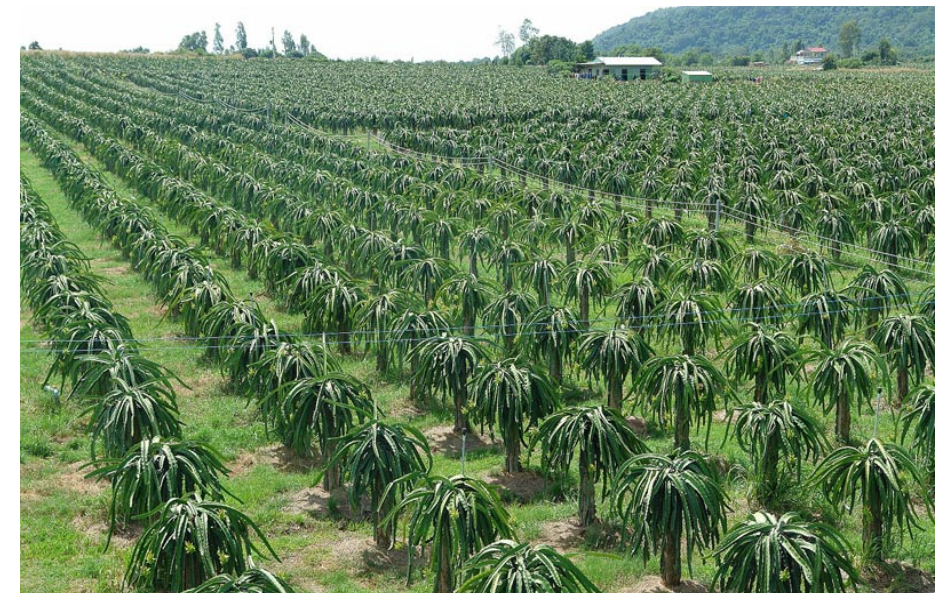

Figure 2: Pitaya plantation 


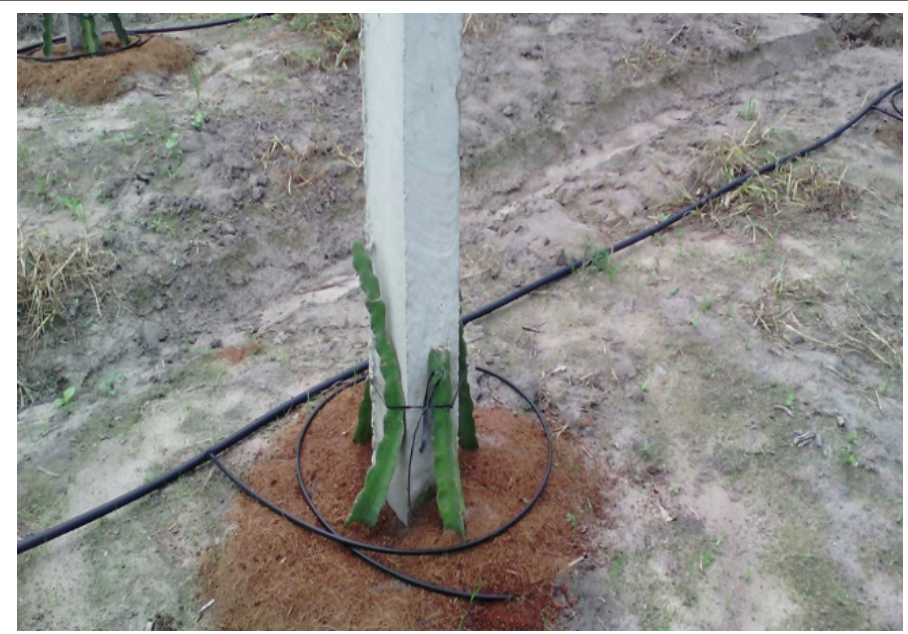

Figure 3: Planting and watering

Dragon fruit trees need humidity to grow, but they cannot survive in waterlogged soil, so pitaya fields need good irrigation and drainage systems. Farmers build drainage ditches and watering pipes along the pillar rows to solve the water problem of pitaya cultivation.

Fertilization depends on the characteristics of the pitaya, soil, weather, and fertilizer. In south Vietnam, farmers fertilize in two periods: basic plantation and exploitation. In the basic development period, they use fertilizer (NPK) and manure to stimulate the development of roots and stems (over two years). In the exploitation period (from the third year), they fertilize four times from March to September to nourish the flower and fruit; they also use NPK and biofertilizer. In artificial crops, the initial fertilization is applied before lighting (15 days), and the second is applied after flower bud appearance ( 5 days after finished lighting).

The dragon fruit tree is susceptible to some diseases; common pests that are a problem for pitaya are mealy bugs and aphids. During the dry season, sunburn can occur, and root rot appears when there is too much water during the rainy season. These diseases can kill pitaya trees or diminish their productivity. In addition, the Xanthomonas Campestris bacterium causes the stem to rot; in particular, Dothiorella fungus triggers brown spots on the fruit and stem, which lowers the quality of dragon fruit (see Figure 4). Vietnamese farmers apply pesticides and bio methods to treat these issues.

Vietnamese farmers can achieve high income from dragon fruit because they apply artificial lighting to encourage blossoming out of season; in this way, they can supply dragon fruit all year round. Despite the high expenses, growers can obtain twice the income associated with only the natural harvest. Previously, farmers used incandescent bulbs $(60 \mathrm{~W})$ to create artificial optical periods; they carried out lighting approximately 15 nights (10 hours per night) and applied 1000 bulbs per hectare (see Figure 5). This method can obtain a positive result, but the electricity fee is high, and productivity is rather modest, especially for H. Undatus (white flesh pitaya). Farmers have begun to use compact fluorescent lamps to diminish spending and obtain higher results. 

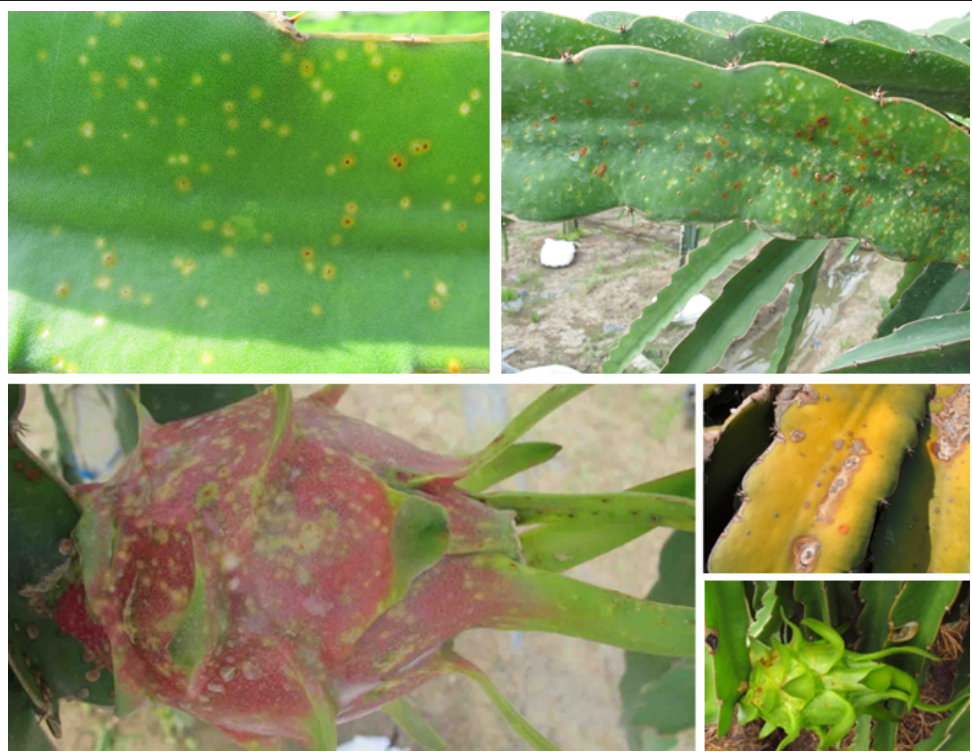

Figure 4: Brown spot disease

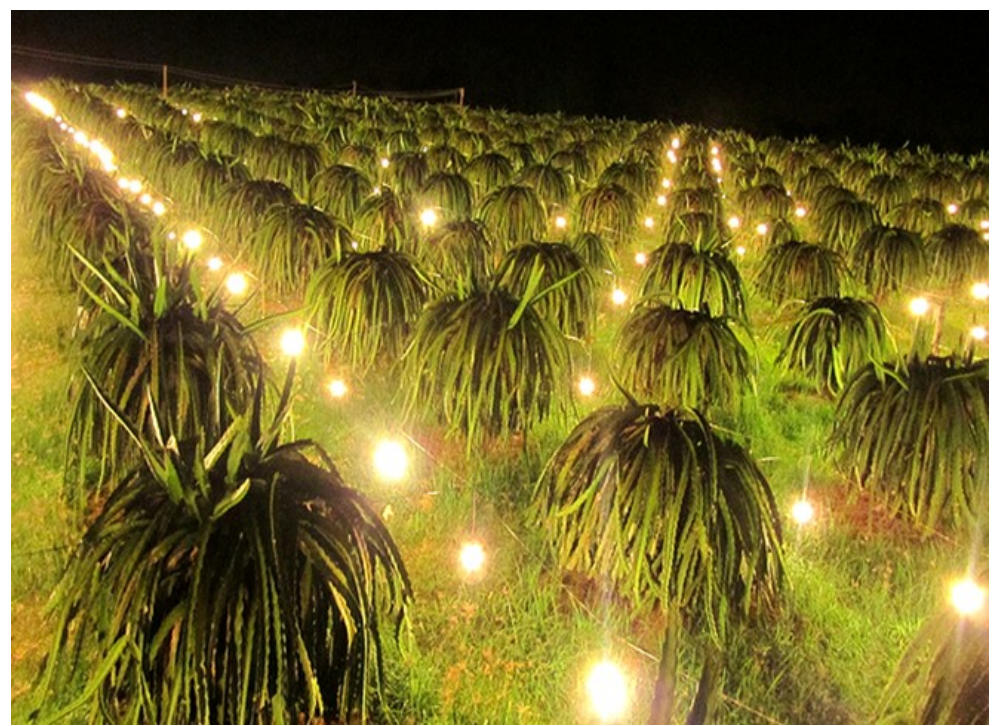

Figure 5: Lighting

To win fastidious markets, Vietnamese farmers apply GAP (good agricultural practices) in their pitaya production. They also use bio methods in caring for dragon fruit trees especially by limiting the application of chemical fertilizers and pesticides. However, this practice raises the cost of the fruit and narrows the markets because of the high price. According to GAP, farmers use biological fertilizer (manure, compost) and natural pesticide (herb, fungi).

\section{Price}

Because $80 \%$ of Vietnamese dragon fruit serves for exportation, the price of pitaya depends on foreign markets, especially China. Normally, the price fluctuates and drops from July to September (natural harvest) and climbs to a peak from December to February (during the holidays of the Lunar New Year). The price of dragon fruit varies from USD 0.4-3 per kilo of fresh fruit at farms. This fluctuation causes a decrease in farmers' income at the time of the natural crop, but the 
solution to this difficulty remains unknown. Currently, China is the main market for Vietnamese pitaya and the largest country of consumption. The dependence of the Vietnamese dragon fruit on one market is a problem because of the pressure of market supply and demand and the intentions of foreign traders. Chinese traders usually reduce the purchase price during the natural crop. Ironically, the price of dragon fruit in the foreign market seems to be kept very high (see Figure 6).

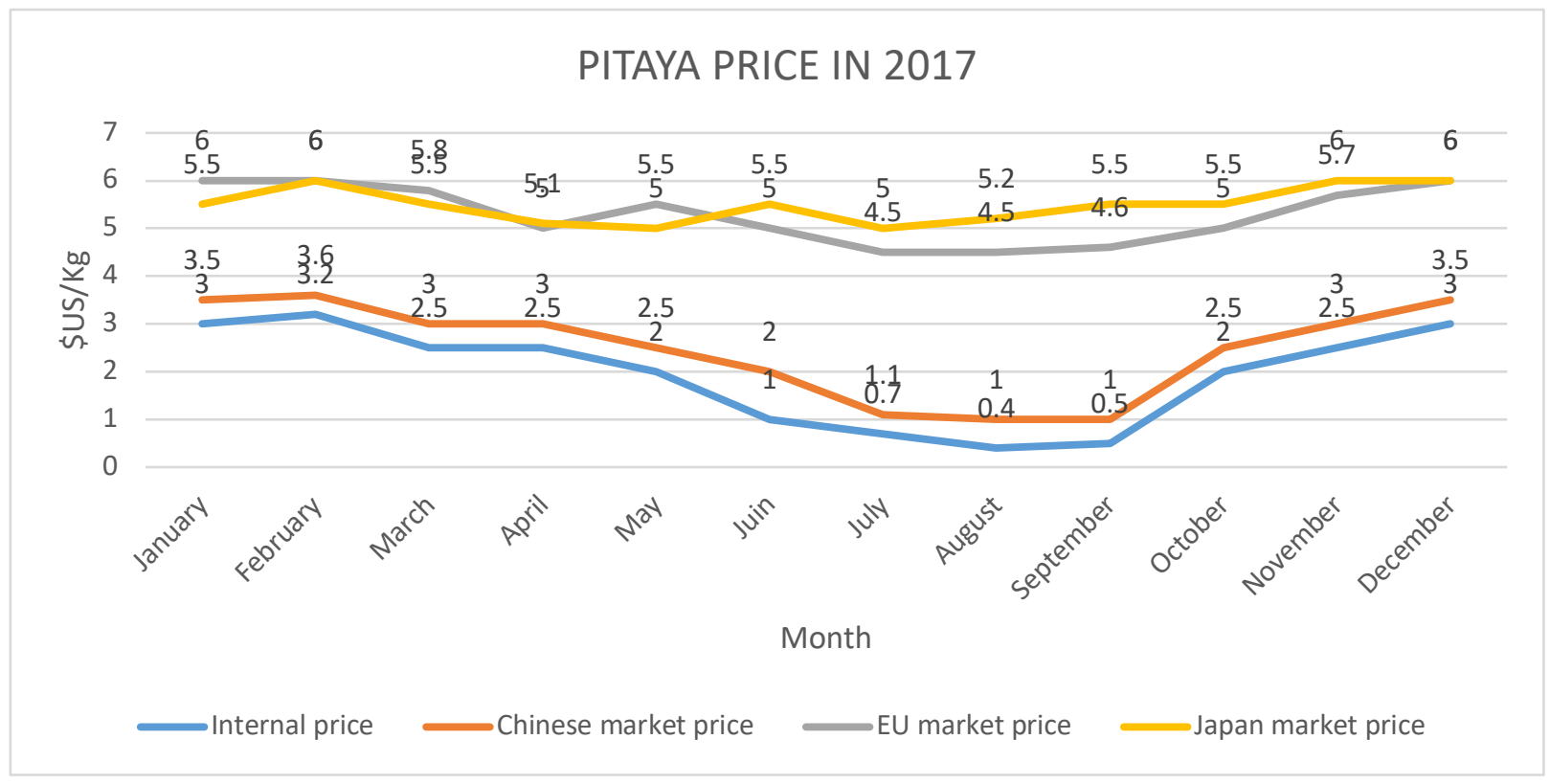

Source: MoIT

Figure 6: Dragon fruit price

\section{Place}

In 2018, dragon fruit production was concentrated in three southern provinces: Binh Thuan (50\%), Tien Giang and Long An. This production concentration is an advantage of the Vietnamese dragon fruit because the planting areas are near a large domestic market and transportation system (Ho Chi Minh City, airport, seaports). Farmers can harvest year round, but a large quantity of dragon fruit appears from July to September. Farmers use refrigerated trailers to transport pitaya to the Chinese market, while plane and ship are the main transportation means for remote markets (Japan, Taiwan, the USA, and Australia). Pitaya plantations tend to be located far from export markets, which is the reason for the high cost of Vietnamese dragon fruit. The government encouraged the development of dragon fruit fields in northern provinces to reduce transportation costs to the Chinese market. This effort was unsuccessful partly because of unsuitable weather and land.

\section{Promotion}

The Vietnamese government and internal trade enterprises have tried to popularize pitaya consumption in many foreign markets, presenting the fruit in many international trade fairs. In trade agreements, the Vietnamese government proposed that partners open the market for Vietnamese dragon fruit. In addition, local enterprises attempt to associate with foreign enterprises in pitaya trade. These endeavors facilitate the entrance of Vietnamese dragon fruit in many markets. However, the quantity of the fruit sold in markets other than the Chinese market 
Nguyen, N. T. (2020). Strategic Marketing for the Vietnamese Dragon Fruit. Archives of Business Research, 8(5). 211-226.

seems rather modest due to the many barriers applied against imported foods, especially fruit. Consequently, the exportation of dragon fruit faces many difficulties.

\section{The distribution system of Vietnamese dragon fruit}

In Vietnam, merchants buy dragon fruit from planters and then resell the fruit to trading enterprises. At the factories, workers classify, clean, hot steam or irradiation treat and package pitaya. These enterprises usually sell dragon fruit to export companies. Depending on the destination market, the fruit is transported by truck, container, ship or plane. Hundreds of cooperatives, trading enterprises and export companies buy and export dragon fruit. The system of wholesale and retail depends on traditional market merchants and supermarkets in the domestic market. In overseas markets, foreign distributors undertake all trading business. The transportation and preservation of pitaya are always disadvantages for the fruit business, especially dragon fruit, because of the fruit's easy spoilage.

\section{The market for Vietnamese dragon fruit and competitors}

Vietnam is currently the largest producer and exporter of dragon fruit in the world, producing as much as one million tons. The domestic market, comprised of mainly large cities, consumes approximately 10-20\% (Ha Noi, HCM). Although dragon fruit is exported to 40 countries, the largest market is the Chinese market, and the annual export quantity reaches $80 \%$ of the total pitaya export volume. The dependence on one market represents a high risk for the dragon fruit business of Vietnam; trouble from China has immediate impacts on the Vietnamese pitaya business. The Vietnamese dragon fruit faces competition from many producers from Asia and Middle America, with China and Thailand considerable competitors. China is the main consumer of Vietnamese pitaya. However, to satisfy the large demand, the Chinese government has issued a policy to encourage pitaya plantations and replace importations from Vietnam. The report of the Chinese Ministry of Agriculture showed that the pitaya farms in Guangxi, Guangdong, Hainan and Fujian covered 35,500 hectares in 2017, and the area covered continues to grow. The Chinese crop season is the same time as that in Vietnam (May to November). This causes much pressure for the Vietnamese main dragon fruit harvest because the price can fall to low levels (see Figure 6). Thailand is a worrisome adversary of Vietnam, although Thai traders also buy Vietnamese dragon fruit and re-export it with Thai brand names. With similar weather to Vietnam, Thai farmers develop pitaya farms in the south of the country. The attraction of the pitaya business also leads to increasing cultivation in many countries, such as the Philippines, Taiwan, Myanmar, and Australia.

\section{THE ZESPRI LESSON OF NEW ZEALAND KIWIFRUIT}

The success of Zespri International Limited is a good experience to learn from in the production and distribution of Vietnamese pitaya. Zespri is now the leading marketer of kiwifruit, selling kiwi in more than 59 countries and managing one-third of the global volume. The history of the kiwifruit is similar to that of the Vietnamese pitaya.

Zespri began to grow kiwifruit in New Zealand in the 1920s and started to export to England in 1952. In the decades following, the quick development of kiwifruit for exportation caused competition for the market. In the 1970s, the government had to form the Kiwifruit Marketing Licensing Authority to control the industry structure and regulate the activities of kiwifruit exporters. This structure enabled the establishment of grade standards and the coordination of approaches to marketing. However, in the late 1980s, the kiwifruit industry of New Zealand faced 
crisis because the large volume produced exceeded the global demand and increased the unfair competition among exporters. In the market, the price of kiwifruit fell to an all-time low. This crisis caused serious damage to New Zealand growers and exporters.

At this time, the New Zealand growers and government began to establish an industrial structure that would put first the interests of farmers and exporters and allow them some market control. Based on visionary leadership and strategic partnerships, the New Zealand kiwifruit industry applied the strategy of building fame for supplying the best kiwifruit. The business aimed to control the quantity and quality of kiwifruit, survey the market demand, and eliminate harmful competition. The active resolutions helped the kiwifruit business overcome the difficult period. Zespri International Limited (1997) was formed in response to the need of kiwifruit production as a global marketing organization that provided a united grower-owned platform to supply the best kiwifruit to the world. Zespri was considered to contribute to overcoming the crisis of the New Zealand kiwifruit.

To solve the problems caused by a crisis, Zespri applied many methods to build a strong reputation of kiwifruit and balance supply and demand. The organization sold kiwifruit in more than 59 countries and opened offices in 21 countries. In addition to balancing the production in New Zealand, Zespri organized kiwifruit orchards in many countries (Italy, France, Japan, and Korea) to reduce transportation fees and supply kiwifruit all year round. The organization also focused on a number of marketing aspects to encourage the kiwifruit business, particularly concentrating on health marketing to raise customer awareness of the health benefits of eating kiwifruit. Zespri also developed new varieties of kiwifruit (green, organic, sweet green, sun gold, and gold kiwifruit) to satisfy the customer demand. The government and industry invest over \$US20 million each year to support farmers to grow high quality, sustainable kiwifruit. Zespri invests heavily in promoting the brand name, enhancing brand awareness and encouraging research to deliver delicious fruit and maintain consistency. In addition, Zespri develops a good supply chain for kiwifruit to allow efficient distribution to customers. With the support of the government and the endeavors of Zespri, New Zealand kiwifruit overcame the crisis of the late 1980s, and Zespri became the leader of the kiwifruit business (Zespri International, 2018).

\section{MARKETING PROPOSALS FOR THE VIETNAMESE DRAGON FRUIT BUSINESS}

There are many actions to take to ensure sustainable development of the Vietnamese dragon fruit exportation. In this study, the author presents some of the most important resolutions for the pitaya, an agricultural product facing potential crisis.

\section{Dragon fruit production and consumption}

One of the serious problems of pitaya production in Vietnam is the control of plantations. The output of the current orchards can exceed one million tons, causing the supply to exceed the demand of existing markets. The government and VINAFRUIT should issue policies to stop the development of new pitaya orchards and build a plan for dragon fruit in Vietnam. The increase in production should depend on the expansion of market demand.

Growers should apply new technologies to assure the quality and productivity of dragon fruit, but the most important issue is improving the quality to satisfy the needs of international consumers. Innovative methods of cultivation are encouraged. Vietnamese farmers apply ferro-concrete pillars 
as supporting posts (2.2 $\mathrm{m}$ high), but the head cadre of the pillar needs improvement (see Figure 7) to allow the even distribution of the branches around the post. The life span of the cadre should be appropriate for the exploitation cycle of pitaya orchards. Experience shows that the density of the pillars should be approximately 1100 to 1200 per hectare to allow the pitaya field to obtain the highest possible productivity. Some new technologies of the supporting system that gain high productivity include reinforced concrete cadre, trellis, and fence to support the dragon fruit tree (see Figure 8-11). These methods can improve the productivity of orchards and reduce the potential for diseases, but they require high investment. These new technologies increase the photosynthesis process of pitaya and simplify harvest and tree care.

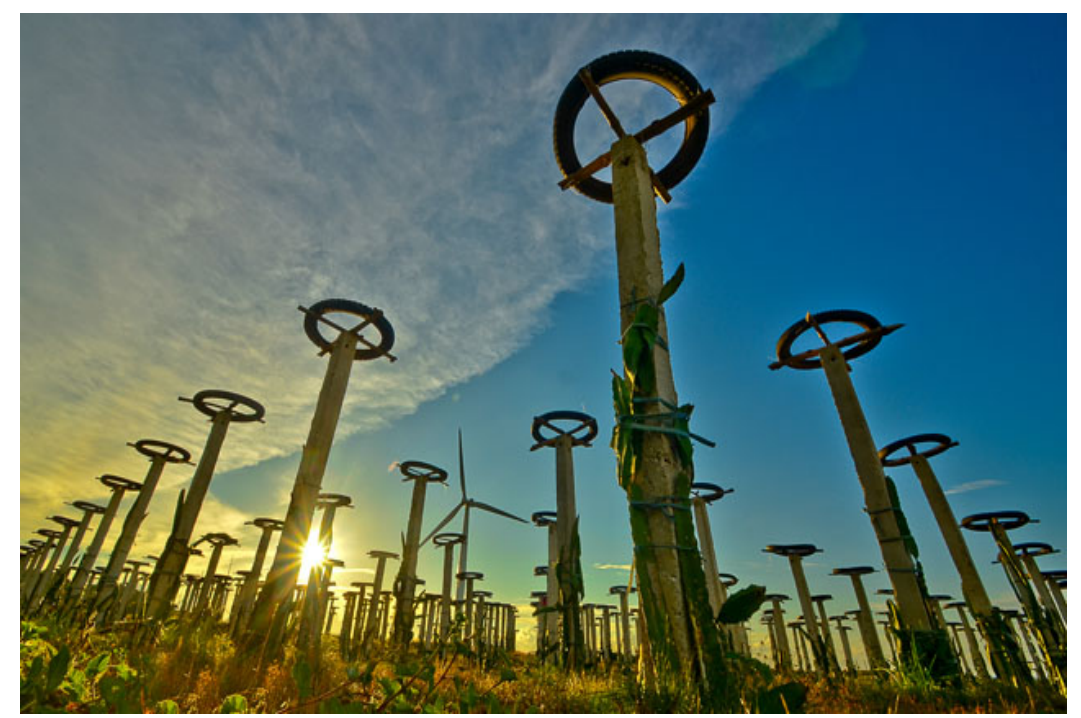

Figure 7: Head cadre of concrete pillar

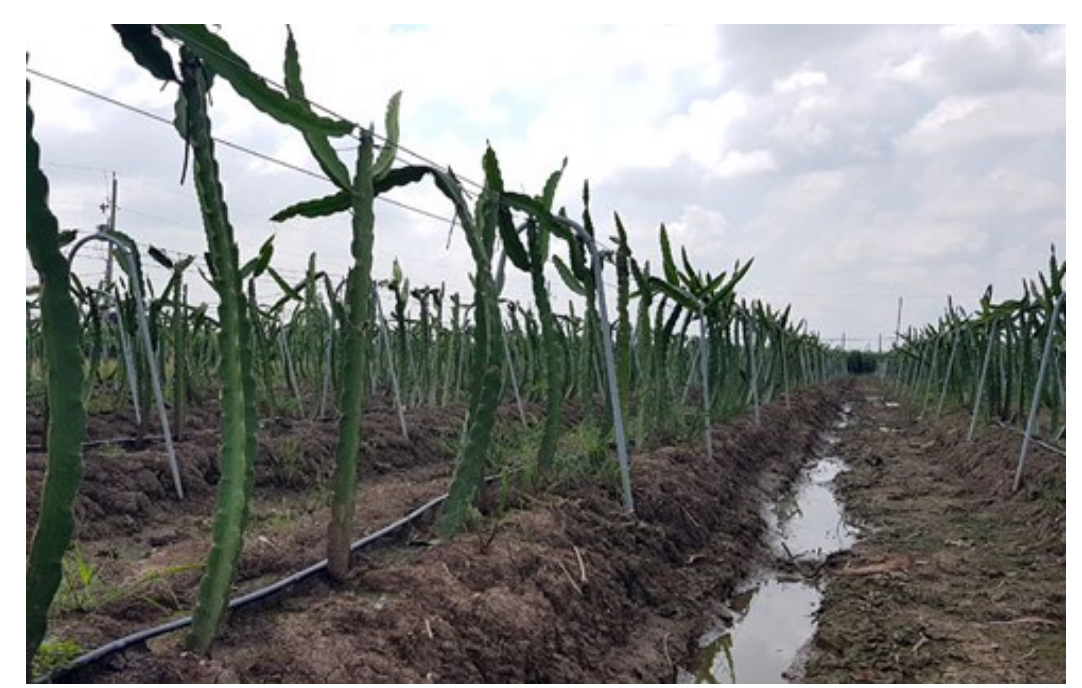

Figure 8: Metal fence support 


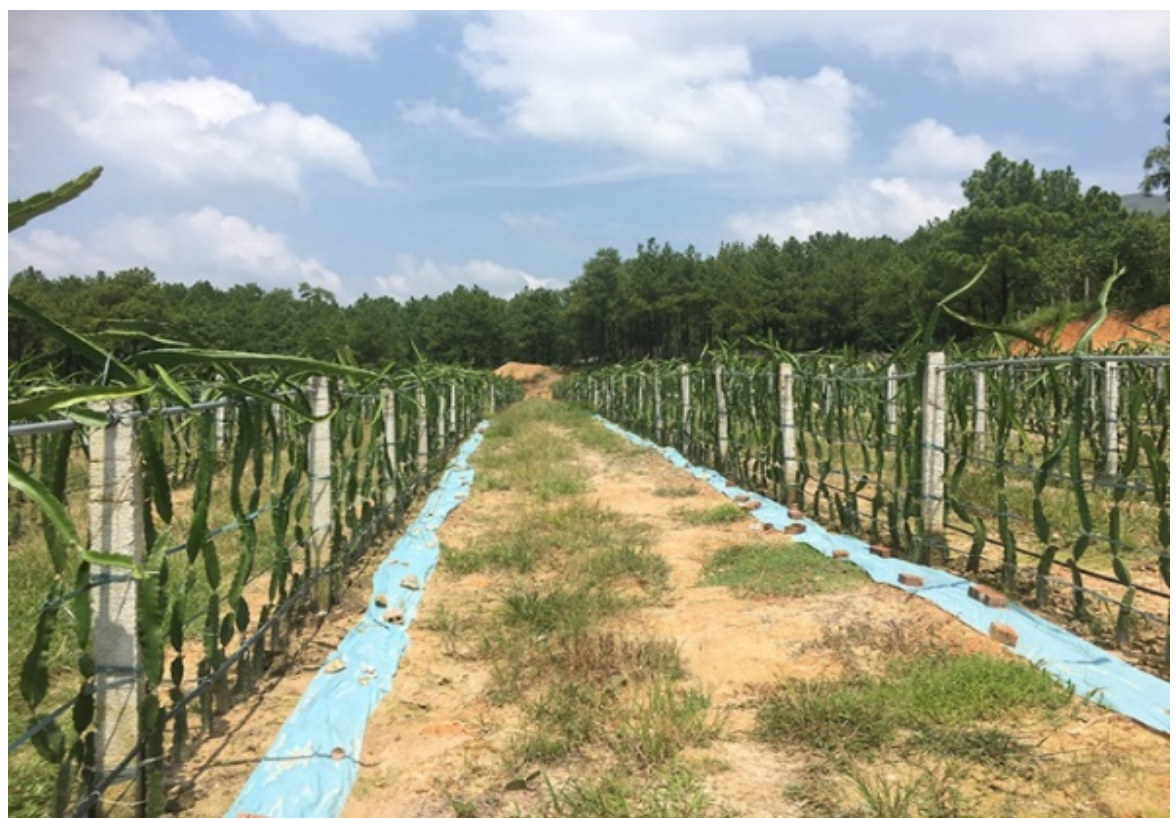

Figure 9: Metal fence and concrete pillar

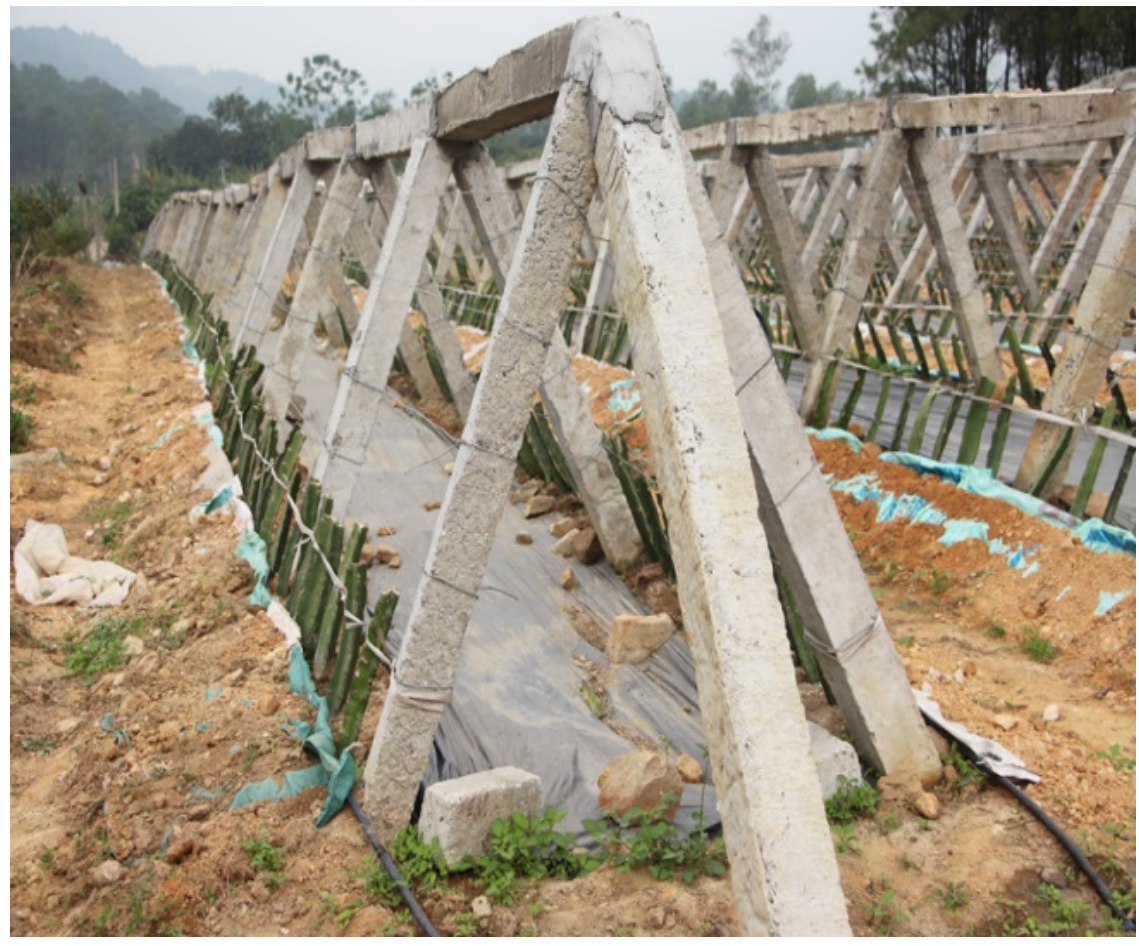

Figure 10: Concrete support cadre 


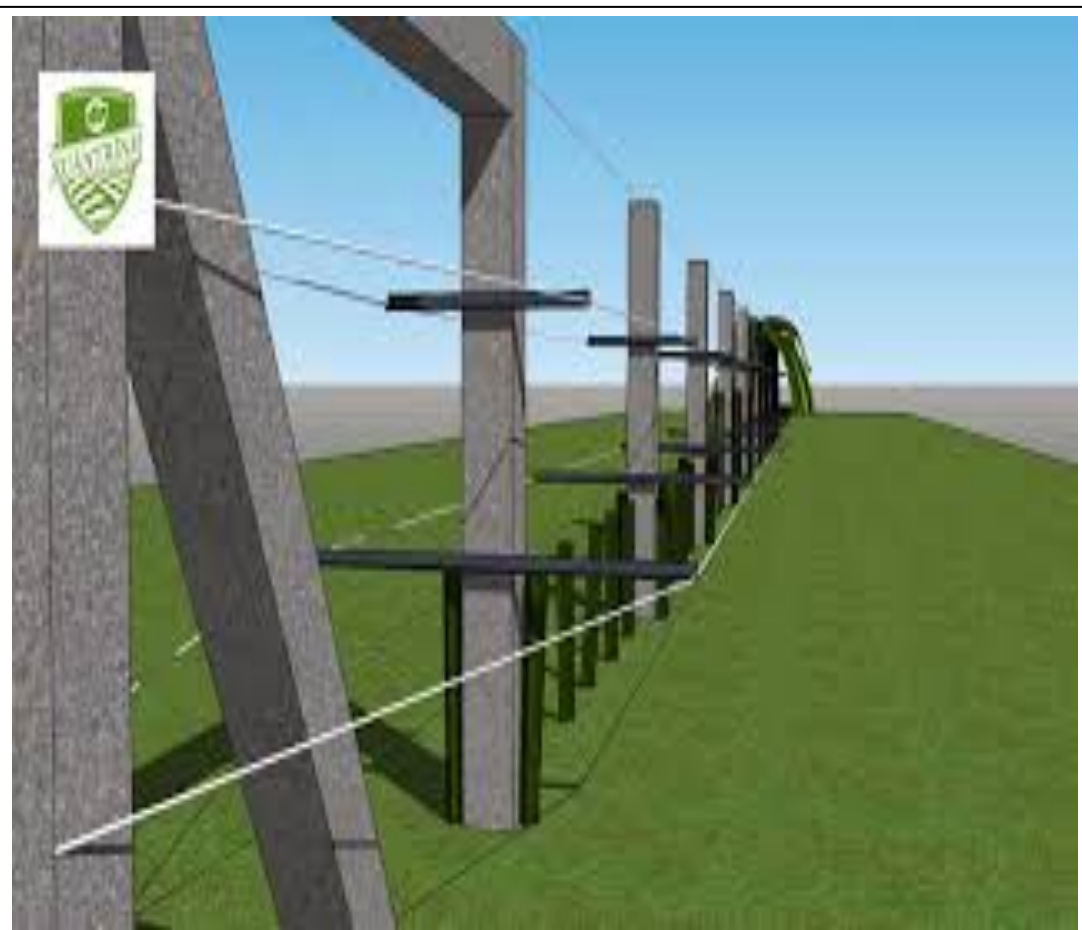

igure 11: Concrete cadre and metal fence

Automatic watering by spray or drip systems is highly evaluated because farmers can save water and energy and reduce production fees. In the dry season, farmers should salvage rice straw to cover the foot of the dragon fruit tree. There are some problems in the fertilization process; growers usually scatter fertilizer on the surface soil, which causes fertilizer loss by evaporation. The dissolving of fertilizer in irrigation water is a good way to save fertilizer and increase its effectiveness. In addition, the change from chemical fertilizer to manure or bio fertilizer is adapted to follow the bio agriculture trend of the market. In fact, the growers of dragon fruit need to apply biopesticides instead of chemical substances; this can protect the environment and assure food safety. The government is encouraging to apply GAP in production to assure a quality of pitaya that satisfies the strict demand of international consumers. The study of varieties is needed to identify new pitaya varieties with higher quality and better weather adaption. Internal and foreign consumers tend to prefer red flesh dragon fruit over white flesh. Growers plan to massively reduce the cultivation of white flesh pitaya to follow the trend, and the government and VINAFRUIT should give advisory opinions. These proposals for improvement require the support of the government and large companies, as small farmers cannot carry out these changes by themselves. Vietnam has an advantage in that its farmers can successfully apply artificial lighting for pitaya blooms. Harvesting at the wrong time enables the supply of dragon fruit year-round, allowing growers to earn higher income than they would supplying only the main harvest. However, the use of incandescent bulbs for lighting consumes much electricity; therefore, the government encourages growers to use compact fluorescent lamps instead (20 W, 1200 lamps per hectare). This application can reduce the use of electricity by $60 \%$ for lighting and reduce the cost for artificial crops by $20 \%$. An important aspect that impacts the price of dragon fruit is the appearance of the fruit. To protect the fruit against insects and fungi and yield high-quality pitaya, growers cover the fruit with bags. All of these methods help improve the quality and price of dragon fruit; however, they require high investment. 


\section{Price}

There is an irony in the pitaya price; whereas the growers' selling price is rather low, the price in the foreign market stays high (see Figure 2). In addition to the supply-demand factor, the costs of transportation and preservation are the main reasons for this difference. To solve this problem, along with production improvement, a good distribution system should be established to reduce shipping fees in transportation and develop new preservation technology.

The balance of output is important. VINAFRUIT should intervene to reduce the quantity of pitaya produced in the main crop of the year. The scattering of production is an effective method to maintain stability of the price of dragon fruit. This is a difficult duty because Vietnamese growers are private, and the average area of cultivation per household is small. Vietnam has no large company (such as Zespri for kiwifruit) to manage the pitaya business. The government should help the business through regulations distributing production areas.

Similar to other agricultural products, branding for Vietnamese dragon fruit is very important for business development. The cooperation of growers, enterprises and governments is necessary to build the brand name of this national product; a good brand name will help increase the consumption of pitaya.

The establishment of a brand name will raise the price of Vietnamese dragon fruit and improve the selling price for farmers. Vietnam has not created a pitaya brand name, which is one reason for the low price. Most pitayas are sold in the market as fresh fruits, which leads to waste and a low price of the main crop because the low quality fruits cannot be salvaged. Furthermore, Vietnam needs to develop the dragon fruit processing industry. Many foods and beverages are currently produced from dragon fruit, such as dried pitaya, tea, wine, juice, beer, powder, food additive, jam, cosmetics, and diet food. Cooks also use dragon fruit in pizza, cocktails, and jelly. This processing will encourage the consumption of pitaya and maintain price stability. However, this development demands good investors and government support.

\section{Place and market}

As Vietnam does not have a strong enterprise leading the pitaya business (such as Zespri of kiwifruit), the government needs to determine the production areas of the country. In practice, the provinces of Binh Thuan, Long An, and Tien Giang have advantages for dragon fruit plantations in terms of soil and climate. The planning of pitaya cultivation requires policy support. Infrastructure, such as electricity, water, and transportation, is necessary for pitaya production and transportation. The government should intervene to curb the spontaneous development of dragon fruit that can cause surplus and national damages.

Vietnam should consider China an important market for dragon fruit because of its population of 1.4 billion and geographical proximity. However, pitaya exportation without a contract with importers causes many risks for Vietnamese enterprises; therefore, the exportation of pitaya should be assured by law. The cooperation of Chinese-Vietnamese enterprises would be beneficial for both countries. India is also a large potential market (1.3 billion people), and Vietnam may sell more dragon fruit there if it promoted a good marketing campaign. Old markets, such as Japan, Korea, Thailand, Taiwan, the EU, and the USA, should be developed with more distribution systems. The cooperation of Vietnamese enterprises and foreign enterprises in the development of 
transportation, preservation and distribution systems is highly valued. The development of such systems would enable Vietnamese companies to more easily approach customers and raise the exportation volume. The neglect of the domestic market is a mistake; with a population of 90 million, Vietnam's internal consumers are not few in number, and a large distribution system is needed to encourage internal consumption in the cities and provinces of Vietnam.

\section{Promotion}

Market expansion is also an important means to prevent dragon fruit crisis. Although Vietnam exports pitaya to over 40 countries the consumption remains modest in all except China. Most consumers are Asians; with the support of the government and the contribution of enterprises, campaigns should be designed to present dragon fruit to Westerners, that they may consume pitaya as a common fruit. Along with participating in traditional trade fairs, the Vietnamese government and enterprises should organize presentations of pitaya with acceptable price to consumers. Marketing will be more successful if marketers are associated with indigenous companies. The promotion of dragon fruit needs the support of government and the active contribution of enterprises. Similar to the case of kiwifruit, the health benefits of eating pitaya and the varieties of dragon fruit should be a focus of advertisement. The use of internet and ecommerce is also a convenient means to advertise dragon fruit and its processed products. Vietnam needs a strong company (like Zespri of New Zealand) to take care of the marketing of pitaya, in the form of fresh fruit or processed products.

\section{CONCLUSION}

Without restructuring intervention, the Vietnamese dragon fruit business will face crisis like the kiwifruit in the 1990s and other Vietnamese fruits at different times. The marketing proposals of this study are based on analysis and experience, but there is a question: who will carry out these proposals? Vietnam is beginning to integrate into the market economy, and it is a member of many international organizations that restrict government intervention in the market. Hopefully, the above marketing methods will raise the price of pitaya in a stable way, increase growers' income and prevent the crisis of the Vietnamese dragon fruit business. The paper would like to present some recommendations.

In a market economy, the government still has an important role in adjusting economic activities. For the Vietnamese dragon fruit business, intervention from the government is urgent to prevent crisis and limit the damages to farmers and the national economy. The government should take charge of the planning of the country's dragon fruit production and define the fruit as a national product. This plan consists of determining areas for plantation, building infrastructure, assigning tasks to various actors, and regulating the quantity produced. When pitaya orchards become too numerous, strict regulation is required to limit the increase in dragon fruit plantations. Governmental support should concentrate on applying science and technology in production and reforming administrative procedures. Financial support is highly valued to help promote dragon fruit when Vietnamese enterprises cannot support themselves. Furthermore, the government should issue policies to encourage strong enterprises to become strong leaders of the pitaya business. A strong company (such as Zespri) would be an asset for the exportation of the dragon fruit of Vietnam. Pitaya is a top-ranking Vietnamese fruit. Through international economic relations, the government has an important role in the development of the dragon fruit business. 
In addition to the government, VINAFRUIT, an NGO, has a very important role. This organization solves problems the government cannot solve because of the regulations of international organizations (such as the World Trade Organization, the Comprehensive and Progressive Agreement for Trans-Pacific Partnership, and free trade agreements). VINAFRUIT can call enterprises to sponsor and contribute to advertising campaigns and raise fruit quality. The association presents to the government and farmers its opinions on controlling the development of pitaya orchards. VINAFRUIT should focus on the dragon fruit markets and competitors and advise the government, enterprises, and growers on pitaya policies. In addition, the association needs to reorganize to respond to the demands of members and farmers.

Vietnamese farmers have the challenges of lacking marketing knowledge, and most of them are small farmers. When they see that one agricultural product yields a higher profit, they swiftly switch to cultivating it. This causes many damages to Vietnamese cultivators. Growers should observe the recommendations of VINAFRUIT and the government to assure the stable development of the pitaya business. In the last few years, most of the fruit has been exported to China, an easy market. However, the Chinese government has issued regulations to control the quality of imported fruit, and the EU inspects the Vietnamese dragon fruit for redundant pesticides and other criteria. Vietnamese growers need to apply GAP to ensure fruit quality. Step by step, new technologies should be put into practice to maintain the brand name of pitaya. To solve the difficulties associated with small areas of cultivation, dragon fruit farmers should establish cooperatives to protect their profit, acquire new technologies and keep up with the changing market.

As of 2018, Vietnam had approximately 500 dragon fruit business enterprises, most of small and medium size. Along with small traders, they form a good system for buying, reselling and exporting farmers' dragon fruit. However, there are also problems, as unfair competition and corruption cause damages to growers and enterprises. These enterprises should join VINAFRUIT for protection against bad competition. The cooperation of growers and enterprises is a wise means to assure the profit of farmers and businessmen through the creation of a controlled chain of dragon fruit production, from the plantation to the market.

In short, there are many problems to solve to obtain the sustainable development of dragon fruit, and the government and VINAFRUIT should establish a marketing plan to support the business against crisis. This plan should define the duties, timeline, and tasks necessary to maintain dragon fruit as a strong Vietnamese agricultural product.

\section{References}

Bucklin R, E. et al, (2008), 'Distribution intensity and new car choice', Journal of Marketing Research, Vol. 45, No. 4, pp. 473-486, doi: 10.1509/jmkr.45.4.473

Clarke C. et al, (2011), 'Fruit products for profit', FAO Diversification booklet, number 16, Rural Infrastructure and Agro- Industries Division Food and Agriculture Organization of The United Nations- Rome.

Jordan Gamble et al, (2011) 'The Marketing Concept in the 21st century: A review of how marketing has been defined since the 1960s', The Marketing Review, Vol. 11, No 3, pp. 227-248, http://dx.doi.org/10.1362/146934711X589444

Kotler and Amstrong (2017), 'Principles of Marketing', Pearson Global Edition, London, UK Kotler and Keller, (2016), 'Marketing Management', Pearson Education Limited, Edinburgh Gate, Harlow, England. 
Nguyen, N. T. (2020). Strategic Marketing for the Vietnamese Dragon Fruit. Archives of Business Research, 8(5). 211-226.

Li Chen Wu et al (2006), 'Antioxidant and antiproliferative activities of red pitaya', Food Chemistry, 95: 319-327

MoIT (2018), Ministry of Industry and Trade of Vietnam, downloaded at: www.moit.gov.vn (July 15, 2018)

Pekka Tuominen, (1996) 'Emerging perspectives in marketing', Publications of the Turku School of Economics and Business Administration, Finland, pp. 185-210

Schiffman and Kanuk, (2004), 'Consumer behavior', Pearson Prentice Hall, Upper Saddle River, New Jersey, USA

Valarie A.Z., (1988), 'Consumer perceptions of price, quality and value: A Means- End Model and Synthesis of Evidence', Journal of Marketing, Vol. 52, No 3, pp. 2-22, doi: 10.2307/1251446

Zespri international, (2018), downloaded at: https://www.zespri.eu/en/ (July 15, 2018) 